\title{
Application of theory of semi-Markov processes to determining distribution of probabilistic process of marine accidents resulting from collision of ships
}

Jerzy Girtler, Prof.,

Gdansk University of Technology, Poland

\begin{abstract}

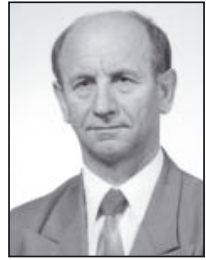

In this paper is presented possible application of the theory of semi-Markov processes to elaborating an eight-state model of the process of occurrence of serviceability state and unserviceability states of sea-going ships making critical manoeuvres during their entering and leaving the ports. In the analysis it was taken into account that sea-going ships are in service for a very long time $t(t \rightarrow \infty)$. The model was elaborated to determine the probability $\left(P_{0}\right)$ of correct execution of critical manoeuvres during ship's entering and leaving the port as well as the probabilities $P_{j}(j=1,2,3, \ldots, 7)$ of incorrect execution of critical manoeuvres by a ship, that leads to marine accidents. It was assumed that such accidents result from: ship's grounding on port approaching fairway, collision with a ship on port approching fairway, collision with a pierhead during passing through port entrance, collision with a hydrotechnical structure during ship's passing through port channels, collision with a port quay during coming alongside it and collision with a ship already moored to the quay. The probability $\left(P_{0}\right)$ was assumed a measure of safe execution of a critical manoeuvre. The probability characterizes possibility of avoiding any collision during ship's entering and leaving the port. The probability $P_{a}=1-P_{0}$ was assumed a measure of occurrence of a collsion and - consequently - marine accident. The probability $P_{a}$ was interpreted as a sum of the probabilities $P_{j}(j=1,2,3, \ldots, 7)$ of occurrence of all the selected events. In summing up the paper, attention was drawn to its merits which - in opinion of this author - are crucial for research on real process of accidents during entering the port and leaving it by sea-going ship in difficult navigation conditions.
\end{abstract}

Key words: critical manoeuvre; port; probability; semi-Markov process; sea-going ship

\section{PRELIMINARY REMARKS}

In maritime shipping the increasing of safety of port manoeuvres associated with ship's entering the port, passing through port channels, and especially with coming alongside the quay and hauling off, is systematically pursued $[1,4,5,14]$. Difficult hydrometeorological conditions result in that the ships sometimes cause collisions. They result from ship's grouding or collision with other ship on port approaching fairway, collision with pierhead or wavebreaker during passing through port entrance, collision with hydrotechnical structure during passing through port channels, collision with port's quay or other ship lain already along quay, during coming alongside the quay and mooring. Therefore the manoeuvres are called critical [1]. Risk of such collisions can be lowered by using tugs to bring ships in the port and next berth them and moor to quay as well as to haul out them from ports. However their use increases operational costs of ships and results in decrease of their profitability. Hence a question arises when to engage towing services is necessary as it is known that the biggest risk of the mentioned collisions takes place in difficult ship traffic conditions, and because such conditions it is easy to make the following errors $[1,4,5,10,14,15]$ :

- underestimating destructive action of sea currents and tides and hydrometeorological conditions,

- unprecise identification of ship propulsion and manoeuvrability qualities in a given ship traffic conditions,

- neglecting (disrespecting) importance of restricted visibility,

- not taking into account current values of speed and direction of wind, its gusts and direction changes.

Without any doubts the most convincing factor which informs on necessity of making use of towing services is the probability of collision occurrence in given traffic conditions during entering the port by ship and executing critical manoeuvres within it. The problem of determining such probability can be characterized in an analytical way by using the theory of semi-Markov processes. The theory is useful for determining occurrence probabilities of events possible to happen during execution of critical manoeuvres by ship 
entering the port, moving inside it as well as leaving the port. This makes it necessary to elaborate a model of process of accidents resulting from execution of such manoeuvres.

\section{MODEL OF PROCESS OF ACCIDENTS RESULTING FROM COLLISIONS OF SHIPS ENTERING THE PORT OR LEAVING IT}

As assumed in the model, the most important events resulting in marine accidents are the following $[1,4,5]$ : $\mathrm{z}_{1}$ - grouding on port approaching fairway, $\mathrm{z}_{2}-$ collision with other ship on port approaching fairway, $z_{3}-$ collision with pierhead during passing through port entrance, $\mathrm{z}_{4}-$ collision with wavebreaker during passing through port entrance, $\mathrm{z}_{5}$ - collision with hydrotechnical structure during passing through port channels, $\mathrm{z}_{6}-$ collision with port's quay during coming alongside it, $\mathrm{z}_{7}$ - ship's collision with other ship lain already along quay - during coming alongside the quay. Each of the events results in ship's damage which involves the ship into unserviceability state $[4,6,7,9]$. Change of the state into serviceability one requires the ship to be renewed by doing an appropriate repair. On completion of the repair the ship regains its operational qualities lost as a result of the collision, that is equivalent to occurrence of the event $\mathrm{z}_{0}$ which means recovering the state of serviceability by the ship. Successive occurrence of the mentioned states $z_{i} \in Z(i=1,2, \ldots, 7)$ forms the process of marine accidents. Occurrence of every marine accident $z_{i} \in Z$ results in arising the unserviceability state $s_{i} \in S^{*}(i=1,2, \ldots, 7)$. Removal of ship's damages due to the mentioned collisions results in occurring the serviceability state of the ship, $s_{0}$. The states can be called the reliability ones as the states $\mathrm{s}_{\mathrm{i}} \in \mathrm{S}$ result from ship's damages (in this case due to collisions) whereas the state $\mathrm{s}_{0}$ takes place as a result of ship's renewal. Obviously, the next collision can happen only when the ship is renewed after occurrence of the former collision. Therefore the model of the process of changes of the mentioned reliability states can be considered the semi-Markov process $\{\mathrm{W}(\mathrm{t}): \mathrm{t} \geq 0\}$ with the set of states $\mathrm{S}=\left\{\mathrm{s}_{\mathrm{i}}\right\} ; \mathrm{i}=0,1,2, \ldots, 7$. Changes of the mentioned states si $(i=0,1,2, \ldots, 7)$ occur in the successive instants $\mathrm{t}_{\mathrm{n}}(\mathrm{n} \in \mathrm{N})$, and in the instant $\mathrm{t}_{0}=0$ the ship is in the state $\mathrm{s}_{0}$. The state $\mathrm{s}_{0}$ lasts til the instant of ship's damage resulting from occurrence of any collision. And, the states $s_{i}(i=1,2, \ldots, 7)$ last until the ship is renewed. Changes of the states $\mathrm{s}_{\mathrm{i}}$ into the states $s_{j}(i, j=0,1,2,3 ; i \neq j)$ occur with the probability $p_{i j}$ after the running time $\mathrm{T}_{\mathrm{ij}}$ which is a random variable. In order to account for the situation in the phase of ship's service it is necessary to describe - in a probabilistic way - its process of accidents due to collisions with taking into account occurrence probabilities of the mentioned states $\mathrm{s}_{\mathrm{i}}(\mathrm{i}=0,1,2, \ldots, 7)$ possible to occur in the particular instants $\mathrm{t}_{0}, \mathrm{t}_{1}, \ldots, \mathrm{t}_{\mathrm{n} 1}, \mathrm{t}_{\mathrm{n}}$ of ship's service time $[2,3,13]$. Therefore the following set of classes of ship's reliability states can be distinguished:

$$
\mathrm{s}_{\mathrm{i}} \in \mathrm{S}(\mathrm{i}=0,1,2, \ldots, 7)
$$

and interpreted as follows:

- $\mathrm{s}_{0}$ - serviceability state,

- $\mathrm{s}_{1}$ - ship's unserviceability state resulting from its grounding on port approaching fairway,

- $\mathrm{s}_{2}$ - ship's unserviceability state resulting from its collision with other ship on port approaching fairway,

- $\mathrm{s}_{3}$ - ship's unserviceability state resulting from its collision with pierhead during ship's passing through port entrance,

- $\mathrm{s}_{4}$ - ship's unserviceability state resulting from its collision with wavebreaker during ship's passing through port entrance,

- $\mathrm{s}_{5}$ - ship's unserviceability state resulting from its collision with a hydrotechnical structure during ship's passing through port channels,

- $\mathrm{s}_{6}$ - ship's unserviceability state resulting from its collision with a port quay during coming alongside it,

- $\mathrm{s}_{7}$ - ship's unserviceability state resulting from its collision with other ship already moored at a port quay - during coming alongside the quay,

It can be assumed that the ship state, $\mathrm{s}_{\mathrm{i}}$, existing in the instant $\mathrm{t}_{\mathrm{n}+1}$ as well as the time interval of lasting the state which has happened in the instant $t_{n}$ depends only on the state which has occurred in the instant $t_{\mathrm{n} 1}$, and not on the states which have happened in the instants $t_{0}, t_{1}, \ldots, t_{n 2}$ as well as not on their lasting time intervals. The assumption is obvious as there is no reletionship between collisions (hence the states $\mathrm{s}_{\mathrm{i}} \in \mathrm{S}^{*}$ are independent events). And, the state $\mathrm{s}_{0}$ depends only on a given state $s_{i}$ and not on the state $s_{i-1}$ directly preceding the state $s_{i}$. Therefore it can be assumed that the process $\{\mathrm{W}(\mathrm{t}): \mathrm{t} \geq 0\}$ is semi-Markovian [5, 6, 8, 12].

The initial distribution of the process is as follows:

$$
\mathrm{P}\left\{\mathrm{W}(0)=\mathrm{s}_{\mathrm{i}}\right\}=\left\{\begin{array}{l}
1 \text { for } \mathrm{i}=0 \\
0 \text { for } \mathrm{i}=1,2,3, \ldots, 7
\end{array}\right.
$$

and, the functional matrix is of the following form:

$$
\mathbf{Q}(\mathbf{t})=\left[\begin{array}{cccccccc}
0 & \mathrm{Q}_{01}(\mathrm{t}) & \mathrm{Q}_{02}(\mathrm{t}) & \mathrm{Q}_{03}(\mathrm{t}) & \mathrm{Q}_{04}(\mathrm{t}) & \mathrm{Q}_{05}(\mathrm{t}) & \mathrm{Q}_{06}(\mathrm{t}) \mathrm{Q}_{07}(\mathrm{t}) \\
\mathrm{Q}_{10}(\mathrm{t}) & 0 & 0 & 0 & 0 & 0 & 0 & 0 \\
\mathrm{Q}_{20}(\mathrm{t}) & 0 & 0 & 0 & 0 & 0 & 0 & 0 \\
\mathrm{Q}_{30}(\mathrm{t}) & 0 & 0 & 0 & 0 & 0 & 0 & 0 \\
\mathrm{Q}_{40}(\mathrm{t}) & 0 & 0 & 0 & 0 & 0 & 0 & 0 \\
\mathrm{Q}_{50}(\mathrm{t}) & 0 & 0 & 0 & 0 & 0 & 0 & 0 \\
\mathrm{Q}_{60}(\mathrm{t}) & 0 & 0 & 0 & 0 & 0 & 0 & 0 \\
\mathrm{Q}_{70}(\mathrm{t}) & 0 & 0 & 0 & 0 & 0 & 0 & 0
\end{array}\right]
$$

The graph of changes of the process, resulting from the functional matrix (3), is presented in Fig. 1.

The functional matrix $\mathbf{Q}(\mathbf{t})$ constitutes the model of changes of the reliability states $s_{i} \in S(i=0,1,2, \ldots, 7)$ of ship. The nonzero elements $\mathrm{Qij}(\mathrm{t})$ of the matrix $\mathrm{Q}(\mathrm{t})$ depend on the distributions of random variables which are the time intervals of lasting the process $\{\mathrm{W}(\mathrm{t}): \mathrm{t} \geq 0\}$ in the states $\mathrm{s}_{\mathrm{i}} \mathrm{S}(\mathrm{i}=0,1,2, \ldots, 7)$. The elements of the functional matrix $\mathrm{Q}(\mathrm{t})$ are the probabilities of transition of the mentioned process from the state $s_{i}$ to the state $s_{j}\left(s_{i}, s_{j} \in S\right)$ during the time not greater than $t$, which are determined as follows: 


$$
\begin{gathered}
\mathrm{Q}_{\mathrm{ij}}(\mathrm{t})=\mathrm{P}\left\{\mathrm{W}\left(\tau_{\mathrm{n}+1}\right)=\mathrm{s}_{\mathrm{j}},\right. \\
\left.\tau_{\mathrm{n}+1} \tau_{\mathrm{n}}<\mathrm{t} \mid \mathrm{W}\left(\tau_{\mathrm{n}}\right)=\mathrm{s}_{\mathrm{i}}\right\}=\mathrm{p}_{\mathrm{ij}} \mathrm{F}_{\mathrm{ij}}(\mathrm{t})
\end{gathered}
$$

where:

$\mathrm{p}_{\mathrm{ij}} \quad-$ probability of one-step transition of uniform Markov chain;

$\mathrm{p}_{\mathrm{ij}} \quad=\mathrm{P}\left\{\mathrm{W}\left(\tau_{\mathrm{n}+1}\right)=\mathrm{s}_{\mathrm{j}} \mid \mathrm{W}\left(\tau_{\mathrm{n}}\right)=\mathrm{s}_{\mathrm{i}}=\lim _{\mathrm{t} \rightarrow \infty} \mathrm{Q}_{\mathrm{ij}}(\mathrm{t}) ;\right.$

$F_{i j}(t)$ - cumulative distribution function of the random variable $\mathrm{T}_{\mathrm{ij}}$ which shows lasting time of the state $\mathrm{s}_{\mathrm{i}}$ of the process $\{\mathrm{W}(\mathrm{t}): \mathrm{t} \geq 0\}$ provided that the next state of the process will be the state $s_{j}$.

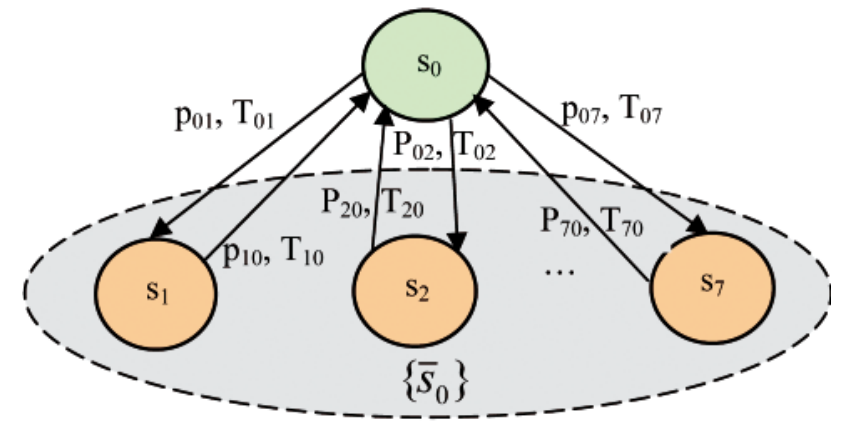

Fig. 1. The graph of changes of the states of the process $\{W(t): t \in T\}$ : $\boldsymbol{s}_{0}-$ serviceability state of a ship, $\left\{\overline{\mathbf{s}}_{0}\right\}$-set of ship's unserviceability states (due to collisions) $\left\{\overline{\boldsymbol{s}}_{0}\right\}=\left\{s_{1}, s_{2}, \ldots, s_{7}\right\}, \boldsymbol{s}_{i} \in \boldsymbol{S}(\boldsymbol{i}=\mathbf{1}, 2, \ldots$,

7) - unserviceability states, $\boldsymbol{p}_{i j}$ - probabilities of changes of the state $s_{i}$ into the state $s_{j}, \boldsymbol{T}_{i j}$-lasting time of the state $s_{i}$ under condition that the next will be the state $s_{j}(i, j=0,1,2, \ldots, 7 ; i \neq j)$

As results from the functional matrix $\mathbf{Q}(\mathbf{t})$ (3), the matrix $\mathbf{P}$ of the probabilities of transition of Markov chain inserted in the process, is as follows $[4,5,6]$ :

$$
\mathbf{P}=\left[\begin{array}{cccccccc}
0 & p_{01} & p_{02} & p_{03} & p_{04} & p_{05} & p_{06} & p_{07} \\
1 & 0 & 0 & 0 & 0 & 0 & 0 & 0 \\
1 & 0 & 0 & 0 & 0 & 0 & 0 & 0 \\
1 & 0 & 0 & 0 & 0 & 0 & 0 & 0 \\
1 & 0 & 0 & 0 & 0 & 0 & 0 & 0 \\
1 & 0 & 0 & 0 & 0 & 0 & 0 & 0 \\
1 & 0 & 0 & 0 & 0 & 0 & 0 & 0 \\
1 & 0 & 0 & 0 & 0 & 0 & 0 & 0
\end{array}\right]
$$

In the process $\{\mathrm{W}(\mathrm{t}): \mathrm{t} \geq 0\}$ the random variables $\mathrm{T}_{\mathrm{ij}}$ are of definite, positive expected values. Therefore its limiting distribution $[4,5,6,11]$ :

$$
\begin{gathered}
P_{j}=\lim _{t \rightarrow \infty} P_{i j}(t)=\lim _{t \rightarrow \infty} P\left\{W(t)=s_{j}\right\} \\
s_{j} \in S(j=0,1,2, \ldots, 7)
\end{gathered}
$$

has the following form:

$$
P_{j}=\frac{\pi_{j} E\left(T_{j}\right)}{\sum_{k=0}^{7} \pi_{k} E\left(T_{k}\right)}
$$

The probabillities $\pi_{\mathrm{j}}(\mathrm{j}=0,1,2,3, \ldots, 7)$ in the formula (7) are the limiting probabilities of the Markov chain inserted in the process $\{W(t): t \geq 0\}$. And, $E\left(T_{j}\right)$ and $E\left(T_{k}\right)$ are expected values of the random variables $T_{j}$ and $T_{k}$, respectively, which show lasting time of ship in the states $\mathrm{s}_{\mathrm{j}}$ and $\mathrm{s}_{\mathrm{k}}$, respectively, independently of which state of it will occur later $[6,11]$.

In order to determine the limiting distribution (7) it is necessary to solve the set of equations which contain the mentioned limiting probabilities $\pi_{j}(j=0,1,2, \ldots, 7)$ of the Markov chain inserted in the process $\{\mathrm{W}(\mathrm{t}): \mathrm{t} \geq 0\}$ as well as the matrix $P$ of probabilities of transition from the state $s_{i}$ to the state $s_{j}$, determined by the formula (5). The set is a system of the following form:

$$
\left.\begin{array}{l}
{\left[\pi_{0}, \pi_{1}, \pi_{2}, \pi_{3}, \pi_{4}, \pi_{5} \pi, \pi_{6}, \pi_{7}\right]=\left[\pi_{0}, \pi_{1}, \pi_{2}, \pi_{3}, \pi_{4}, \pi_{5}, \pi_{6}, \pi_{7}\right] \cdot \mathbf{P}} \\
\sum_{\mathrm{k}=0}^{7} \pi_{\mathrm{k}}=1
\end{array}\right\}
$$

As a result of solving the set of equations (8) it is possible - by making use of the formula (7) - to obtain the following relations:

$$
\left.\begin{array}{l}
\mathrm{P}_{0}=\frac{\mathrm{E}\left(\mathrm{T}_{0}\right)}{\mathrm{E}\left(\mathrm{T}_{0}\right)+\sum_{\mathrm{k}=0}^{7} \mathrm{p}_{0 \mathrm{k}} \mathrm{E}\left(\mathrm{T}_{\mathrm{k}}\right)}, \mathrm{P}_{1}=\frac{\mathrm{p}_{01} \mathrm{E}\left(\mathrm{T}_{1}\right)}{\mathrm{E}\left(\mathrm{T}_{0}\right)+\sum_{\mathrm{k}=0}^{7} \mathrm{p}_{0 \mathrm{k}} \mathrm{E}\left(\mathrm{T}_{\mathrm{k}}\right)}, \mathrm{P}_{2}=\frac{\mathrm{p}_{02} \mathrm{E}\left(\mathrm{T}_{2}\right)}{\mathrm{E}\left(\mathrm{T}_{0}\right)+\sum_{\mathrm{k}=0}^{7} \mathrm{p}_{0 \mathrm{k}} \mathrm{E}\left(\mathrm{T}_{\mathrm{k}}\right)} \\
\mathrm{P}_{3}=\frac{\mathrm{p}_{03} \mathrm{E}\left(\mathrm{T}_{3}\right)}{\mathrm{E}\left(\mathrm{T}_{0}\right)+\sum_{\mathrm{k}=0}^{7} \mathrm{p}_{0 \mathrm{k}} \mathrm{E}\left(\mathrm{T}_{\mathrm{k}}\right)}, \mathrm{P}_{4}=\frac{\mathrm{p}_{04} \mathrm{E}\left(\mathrm{T}_{4}\right)}{\mathrm{E}\left(\mathrm{T}_{0}\right)+\sum_{\mathrm{k}=0}^{7} \mathrm{p}_{0 \mathrm{k}} \mathrm{E}\left(\mathrm{T}_{\mathrm{k}}\right)}, \mathrm{P}_{5}=\frac{\left.\mathrm{p}_{05} \mathrm{E} \mathrm{T}_{5}\right)}{\mathrm{E}\left(\mathrm{T}_{0}\right)+\sum_{\mathrm{k}=0}^{7} \mathrm{p}_{0 \mathrm{k}} \mathrm{E}\left(\mathrm{T}_{\mathrm{k}}\right)} \\
\mathrm{P}_{6}=\frac{\mathrm{p}_{06} \mathrm{E}\left(\mathrm{T}_{6}\right)}{\mathrm{E}\left(\mathrm{T}_{0}\right)+\sum_{\mathrm{k}=0}^{7} \mathrm{p}_{0 \mathrm{k}} \mathrm{E}\left(\mathrm{T}_{\mathrm{k}}\right)}, \mathrm{P}_{7}=\frac{\mathrm{p}_{07} \mathrm{E}\left(\mathrm{T}_{7}\right)}{\mathrm{E}\left(\mathrm{T}_{0}\right)+\sum_{\mathrm{k}=0}^{7} \mathrm{p}_{0 \mathrm{k}} \mathrm{E}\left(\mathrm{T}_{\mathrm{k}}\right)}
\end{array}\right\}
$$

The probability $\mathrm{P}_{0}$ is the limiting probability that during a longer service time (theoretically at $\mathrm{t} \rightarrow \infty$ ) sea-going ship which executes critical manoeuvres, is in the state $\mathrm{s}_{0}$. Hence the probability determines correct execution of critical manoeuvres during which the ship does not suffer any collision and consequently no marine accident happens. And, the probabilities $\mathrm{P}_{\mathrm{j}}(\mathrm{j}=1,2, \ldots, 7)$ are the limiting probabilities of occurrence of the states $\mathrm{s}_{\mathrm{j}} \in \mathrm{S}(\mathrm{j}=1,2, \ldots, 7)$ of sea-going ship at $\mathrm{t} \rightarrow \infty$, i.e. the probabilities of 
remaining the ship in the unserviceability states resulting from the mentioned collisions $\mathrm{z}_{\mathrm{i}} \in \mathrm{Z}(\mathrm{i}=1,2, \ldots, 7)$.

The example realization of the process $\{\mathrm{W}(\mathrm{t}): \mathrm{t} \geq 0\}$, which illustrates occurring the ship's reliability states $s \in S(j=$ $=0,1,2, \ldots, 7)$ during ship's service, is presented in Fig. 2 . In order to calculate values of the probabilities $P_{j}(j=0,1,2$, $\ldots, 7)$ it is necessary to estimate $\mathrm{p}_{\mathrm{ij}}$ and $\mathrm{E}\left(\mathrm{T}_{\mathrm{j}}\right)$

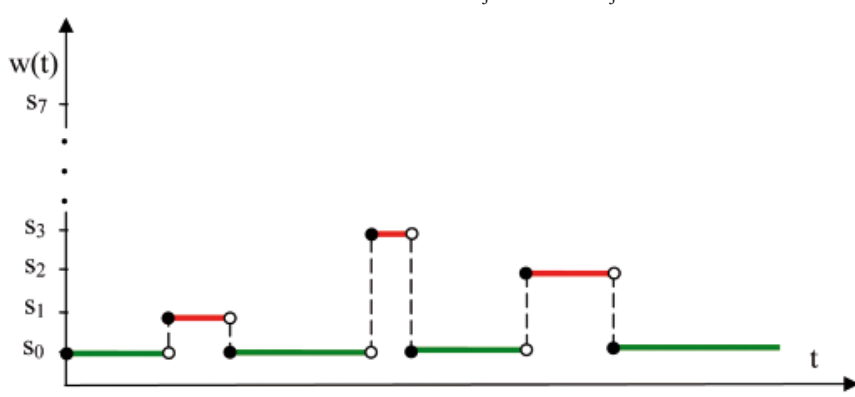

Fig. 2. The example of the process $\{W(t): t \geq 0\}$ for the considered ship: $\boldsymbol{s}_{0}-$ serviceability state of the ship, $\boldsymbol{s}_{1}$-unserviceability state of the ship, as a result of grounding on the approach way to port, $\boldsymbol{s}_{2}$ - unserviceability state of the ship, as a result of collision with another ship on the approach line to port, $s_{3}-$ unserviceability state of the ship, as a result of crashing into an entrance head when passing by

Estimating the probabilities $\mathrm{p}_{\mathrm{ij}}$ and expected values $\mathrm{E}\left(\mathrm{T}_{\mathrm{j}}\right)$ is possible after obtaining the realization $\mathrm{w}(\mathrm{t})$ of the process $\{\mathrm{W}(\mathrm{t})$ : $\mathrm{t} \in 0\}$ within an appropriately long investigation time interval, i.e. for $\mathrm{t} \in\left[0, \mathrm{t}_{\mathrm{b}}\right]$, where the investigation time of the process, $t_{b}>>0$. It is then possible to set the numbers $n_{i j}(i, j=0,1,2,3$; $\mathrm{i} \neq \mathrm{j}$ ), of transitions of the process $\{\mathrm{W}(\mathrm{t}): \mathrm{t} \in 0\}$ from the state $\mathrm{s}_{\mathrm{i}}$ to $\mathrm{s}_{\mathrm{j}}$ in an approporiately long time and to determine values of the estimator $\hat{P}_{i j}$ of the unknown probability $p_{i j}$. Statistic is the most credible estimator of the transition probability $\mathrm{p}_{\mathrm{ij}}$ $[6,11]$

$$
\hat{P}_{i j}=\frac{N_{i j}}{\sum_{j} N_{i j}}, \quad i \neq j ; i, j=0,1,2,3
$$

whose value:

$$
\hat{\mathrm{p}}_{\mathrm{ij}}=\frac{\mathrm{n}_{\mathrm{ij}}}{\sum_{\mathrm{j}} \mathrm{n}_{\mathrm{ij}}}
$$

is an estimation of the unknown transition probability $p_{i j}$.

From the mentioned run of $\mathrm{w}(\mathrm{t})$ of the process $\mathrm{W}(\mathrm{t})$ it is also possible to obtain the realizations $\mathrm{t}_{\mathrm{i}}^{(\mathrm{m})}, \mathrm{m}=1,2, \ldots, \mathrm{n}_{\mathrm{ij}}$, of the random variables $T_{j}$. Application of the point estimation makes it possible to easily estimate $\mathrm{E}\left(\mathrm{T}_{\mathrm{j}}\right)$ by counting arithmetic mean value of the realization $\mathrm{t}_{\mathrm{j}}(\mathrm{m})[3,13]$.

$E\left(T_{j}\right)$ is expected value of the random variable $T_{j}(j=0$, $1,2, \ldots, 7)$ equivalent to lasting time of the state $s_{j} \in S(j=$ $=0,1,2, \ldots, 7)$ of the process $\{\mathrm{W}(\mathrm{t}): \mathrm{t} \geq 0\}$ independently of that to which state the process goes through from the state in question.

The expected values $E\left(T_{j}\right)$ depend on the expected values $E\left(T_{i j}\right)$ as well as the probabilities $p_{i j}$, as follows:

$$
E\left(T_{j}\right)=E\left(T_{i}\right)=\sum_{j} p_{i j} E\left(T_{i j}\right), i, j=\overline{0,7} ; i \neq j
$$

The probability $\mathrm{P}_{0}$ can be considered a measure of safe operation of ship. And, the probability:

$$
\overline{\mathrm{P}}_{0}=\sum_{\mathrm{j}=1}^{7} \mathrm{P}_{\mathrm{j}}
$$

can be considered a measure which characterizes possibility of collision occurrence during executing critical manoeuvres by ship entering the port and moving over it in difficult conditions.
In order to obtain values (approximated of course) of the probabilities $P_{j}(j=0,1,2, \ldots, 7)$ it is necessary to estimate $p_{i j}$ and $E\left(T_{j}\right)$, as it was already mentioned. In the case when the probability is greater than $\left(\mathrm{P}_{\mathrm{a}}\right)$, i.e. that accepted by shipowner, $\left(\overline{\mathrm{P}}_{0}>\mathrm{P}_{\mathrm{a}}\right)$, the ship operator should angage towing services. Tugs are capable of aiding the ship either in safe entering the port or leaving it.

\section{COMMENTSS AND CONCLUSIONS}

The proposal, presented in this paper, of determining the probability which characterizes possible occurrence of marine accident during ship's entering the port or leaving it, deals only with the seven-state set of events resulting in collisions as well as the state of correct execution of critical manouvre. If requested, the proposed model of the process of accidents associated with incorrect execution of critical manoeuvres may be extended by taking into account ship's unserviceability states caused by additional collisions.

To make rational operational decisions connected with the use of tugs for moving the ship into and out of port in ship's operational phase, with accounting for its safety, is possible in the case of knowing, a.o.:

- the probabilities $P_{j}(j=1,2,3, \ldots, 7)$ of occurrence of accident during execution of critical manoeuvres by the ship entering the port or leaving it,

- the probabilities $\mathrm{P}_{0}$ of correct execution of critical manoeuvres by the ship, i.e. its safe entering the port or leaving it.

To determine of the mentioned probabilities was applied the theory of semi-Markov processes.

Possible application of semi-Markov process, instead of Markov process, for modelling sequential occurrence of the mentioned situations in which ship's moving can be realized during execution of critical manoeuvres, results from that it should be expected that the random variables $T_{i j}$ and $T_{i}$ have arbitrary distributions concentrated in the set $R_{+}=[0,+\infty)$. Application of Markov process would be justified if only it were be allowed to assume that the random variables $T_{i j}$ and $\mathrm{T}_{\mathrm{i}}$ have exponential distributions.

The presented model of the process of marine accidents resulting from collisions during execution of critical manoeuvres, can be of practical importance because it is easy to determine estimators for the transition probabilities $\mathrm{p}_{\mathrm{ij}}$ and to estimate the expected values $\mathrm{E}\left(\mathrm{T}_{\mathrm{j}}\right)$. It should be simultaneously taken into account that the point estimation of the expected value $E\left(T_{j}\right)$ does not make it possible to determine accuracy of its estimation. To assess such accuracy is possible by using the interval estimation $[3,13]$ in which is determined the confidence interval $\left[\mathrm{t}_{\mathrm{d},}, \mathrm{t}_{\mathrm{g} j}\right]$ of random limits, which contains the expected value $\mathrm{E}\left(\mathrm{T}_{\mathrm{j}}\right)$ with a determined probability (confidence level) $\beta$.

\section{BIBLIOGRAPHY}

1. Abramowicz-Gerigk T.: Safety of critical manoeuvres of ships in sea highway transport system(in Polish). Prace Naukowe (Scientific bulletin). Transport, issue 83. Oficyna Wydawnicza Politechniki Warszawskiej (Publishing House of Warsaw University of Technology), Warszawa 2012.

2. Benjamin J. R., Cornell C. A.: Calculus of probability, mathematical statistics and decision-making theory for engineers (in Polish). WNT (Scientific Technical Publishers), Warszawa 1977.

3. Firkowicz S.: Statistical assessment of quality and reliability of electronic lamps (in Polish). WNT (idem), Warszawa 1963. 
4. Girtler J., Kuszmider S., Plewiński L.: Selected problems of operation of sea-going ships in the aspect of safety at sea (in Polish). Monograph. WSM (Szczecin Maritime Academy), Szczecin 2003.

5. Girtler J., Kitowski Z., Kuriata A.: Safety of ship at sea. Systematic approach (in Polish). WKit (Transport and Telecommunication Publishers), Warszawa 1995.

6. Girler J.: Controlling the operation process of ship diesel engines on the basis of a diagnostic decision-making model (in Polish). Zeszyty Naukowe AMW(Scientific Bulletins of Polish Naval Academy), No. 100A, Gdynia 1989.

7. Girtler J.: Suggestion of interpretation of action and the rule of taking decision with regard to safety of sea ships traffic. Zagadnienia Eksploatacji Maszyn (Operational Problems of Machines), issue 2(122), vol. 35, 2000.

8. Girtler J.: Diagnostics - a condition for controlling ship diesel engines in service (in Polish). Study No. 28. WSM (Szczecin Maritime Academy), Szczecin 1997.

9. Girtler J.: Availability of sea transport means. Archives of Transport. Polish Academy of Sciences Committee of Transport. Quarterly, vol. 9, iss. 3-4, Warsaw 1997.

10.Girtler J.: Possibility of valuation of marine diesel engines. Journal of Polish CIMAC, No. 1,Vol. 4,, Gdańsk 2009.

11.Grabski F.: Theory of semi-Markov processes of operation of technical objects (in Polish). Zeszyty Naukowe WSMW (AMW)
(Scientific Bulletins of Polish Naval Academy), No. 75A, Gdynia 1982.

12.Jaźwiński J., Borgoń J.: Operational reliability and safety of flights (in Polish). WKit

(Transport and Telecommunication Publishers), Warszawa 1989.

13.Krzysztofiak M., Urbanek D.: Statistical methods (in Polish). PWN (Polish Scientific Publishers), Warszawa 1979.

14.Plewiński L.: Accidents at sea. Collisions of ships (in Polish). Publ. WSM (Szczecin Maritime Academy), Szczecin 2000.

15.Wiśniewski B.: Wind-generated waves (in Polish). Rozprawy i studia (Dissertations and studies), Vol. (CCCIV) 230, Publ. Uniwersytet Szczeciński (Szczecin University), Szczecin 1998.

\section{CONTACT WITH THE AUTHOR}

Jerzy Girtler, Prof.

Department of Ship Power Plants

Faculty of Ocean Engineering and Ship Technology

Gdansk University of Technology

Narutowicza 11/12

80-233 Gdansk, POLAND

e-mail: jgirtl@pg.gda.pl 